\title{
RC\&C
}

Revista de Contabilidade e Controladoria

\section{ESTRUTURA DE PROPRIEDADE E CONSERVADORISMO CONDICIONAL EM INSTITUIÇÕES BANCÁRIAS NO BRASIL}

OWNERSHIP STRUCTURE AND CONDITIONAL CONSERVATISM IN BANKING INSTITUTIONS IN BRAZIL

Mestrando em Ciências Contábeis pelo CEPCON | Faculdade de Ciências Econômicas - FACE | Av. Antonio Carlos, 6627 | Belo Horizonte - MG.

Jacqueline Veneroso Alves da Cunha

Professora Adjunta do Departamento de Ciências Contábeis da Universidade Federal de Minas Gerais - UFMG | CEPCON - Faculdade de Ciências Econômicas FACE | Av. Antonio Carlos, 6627 | Belo Horizonte - MG | Telefone: (31) 34097575 | E-mail: jvac@face.ufmg.br

\section{RESUMO}

Diversos países passaram a utilizar as normas emitidas pelo IASB. A lei 11.638/07 obrigou as empresas brasileiras de capital aberto a conduzirem sua contabilidade conforme as normas internacionais do IASB, traduzidas pelo Comitê de Pronunciamentos Contábeis. O objetivo do estudo foi verificar o value relevance da informação contábil, especificamente, Pesquisa e Desenvolvimento (P\&D), em empresas brasileiras e, assim, determinar se a padronização internacional elevou a relevância de P\&D para o mercado brasileiro. Foram coletados dados no período de 2003 a 2007 e 2008 a 2012, anterior e posterior à lei 11.638/07 respectivamente, 


\begin{abstract}
nas empresas que divulgaram dados de Pesquisa e Desenvolvimento listadas na BM\&FBOVESPA. Fez-se uso de análise estatística com base no $\mathrm{R}^{2}$, e na significância dos coeficientes estimados. Os resultados demonstram que, com a implementação dos padrões internacionais e as mudanças na contabilização de P\&D pelo CPC 06, a informação P\&D passou a ser relevante para o mercado brasileiro.
\end{abstract}

Palavras chave: Informação contábil; Pesquisa e Desenvolvimento. Convergência Contábil.

\title{
ABSTRACT
}

Several countries have begun to use the standards issued by the IASB. Law 11638/07 forced the Brazilian public companies to conduct their accounting in accordance with international standards of the IASB, translated by the Accounting Pronouncements Committee. The aim of the study was to investigate the value relevance of accounting information, specifically, research and development (R\&D), in Brazilian companies and thereby determine whether the international standardization increased the relevance of R\&D for the Brazilian market. We collected data from 2003 to 2007 and from 2008 to 2012, before and after the Law $11638 / 07$ respectively, the companies that have reported data for Research and Development listed on BM\&FBOVESPA. We used statistical analysis based on $\mathrm{R}^{2}$, and the significance of the estimated coefficients. The results demonstrate that with the implementation of international standards and changes in accounting for R\&D by CPC 06, the R\&D information has become relevant to the Brazilian market.

Keywords: Accounting information; Research and Development; Accounting Convergence.

\section{INTRODUÇÃO}

O princípio do conservadorismo, definido como o reconhecimento mais oportuno de perdas em relação aos ganhos, tem caracterizado a prática contábil há séculos (BASU, 1997). O conservadorismo é considerado um dos mais importantes atributos qualitativos da contabilidade, e seu papel econômico e resiliência tem sido foco de debates e pesquisas pelos reguladores, praticantes e acadêmicos (WATTS, 2003; GOTTI, 2008).

O International Accounting Statements Boards (IASB), por sua vez, prefere que a informação contábil seja neutra, livre de viés, e se opõe à inclusão do conceito de conservadorismo como uma característica desejável da informação contábil, sendo excluída da sua estrutura conceitual em 2010. No entendimento do IASB, se o conservadorismo for praticado, não haverá representação fiel da informação divulgada. Assim, o conservadorismo não é um princípio adotado pelo citado organismo, o qual espera que as demonstrações financeiras sejam compreensíveis, relevantes, confiáveis e comparáveis, observada a sua neutralidade (GOTTI, 2008).

Revista de Contabilidade e Controladoria, ISSN 1984-6266

Universidade Federal do Paraná, Curitiba, v. 8, n.3, p. 8-27, set./dez. 2016. 
Entretanto, a visão dos padronizadores não é unanimemente compartilhada por acadêmicos e praticantes. Sartorelli, Martins e Silva (2012) registram que os que discordam da retirada do conservadorismo argumentam que é impossível atingir a neutralidade no relatório contábil, porquanto a informação contábil é uma ferramenta voltada para influenciar o processo decisório, e, portanto, nunca será neutra. Watts (2003) ressalta que o conservadorismo contábil não é tão ilógico quanto parece, mas, de fato, é conduzido por algumas forças econômicas fundamentais, e constitui um eficiente mecanismo de resposta ao ambiente econômico, legal e político em que a firma opera.

A literatura sobre conservadorismo contábil fornece algumas razões para a demanda pelo conservadorismo condicional: o conservadorismo reduz problemas de risco moral causados por partes com informações assimétricas, remunerações assimétricas, horizontes limitados e responsabilidade limitada; o conservadorismo reduz os custos esperados de litígios, porque a probabilidade de sua ocorrência é maior quando os ativos líquidos e os lucros estão sobrevalorizados; o conservadorismo reduz o valor presente das responsabilidades fiscais, quando o imposto a ser pago é influenciado pelo resultado contábil; e o conservadorismo auxilia os reguladores a reduzir os custos políticos associados à sobrevalorização dos ativos líquidos e dos lucros (BASU, 1997; HOLTHAUSEN, WATTS, 2001; WATTS, 2003; LAFOND, ROYCHOWDHURY, 2007; LAFOND, WATTS, 2008; BONÁ-SÁNCHEZ, PEREZ-ALEMÁN, SANTANA-MARTÍN, 2009).

Diversos estudos demonstraram também a influência do regime legal/judicial do país (codelaw/common-law) e do impacto da participação governamental na economia sobre o conservadorismo (BALL, KOTHARI, ROBIN, 2000; BUSHMAN, PIOTROSKI, 2006).

Entretanto, o enfoque mais estudado do conservadorismo é sua função de mecanismo de governança corporativa relacionado à necessidade de preservar cláusulas contratuais pactuadas, para resolver os conflitos de interesses entre acionistas e credores, devido às suas divergentes estruturas de recompensa (WATTS, ZIMMERMAN, 1986; WATTS, 2003; BALL, SHIVAKUMAR, 2005). Na medida em que a qualidade informacional contábil, ligada ao conservadorismo condicional, tem a capacidade de reduzir os custos de agência, desse modo impedindo a expropriação de recursos dos provedores de capital, ela se relaciona intimamente com a governança corporativa.

Na percepção de Silveira (2002), dentre os mecanismos internos de controle de governança, na busca da redução dos custos de agência, destacam-se o conselho de administração, o sistema de remuneração dos executivos e a estrutura de propriedade. Por sua vez, a avaliação dos benefícios e dos custos da escolha da estrutura de propriedade de uma empresa pode ser racionalizada em termos do trade-off entre incentivos para monitorar os executivos - que podem resultar na criação de valor para a empresa - e ganhos de liquidez e diversificação - a renúncia destes pode incitar a busca de benefícios privados de controle (ALDRIGHI, MAZZER NETO, 2007).

Silveira (2002) descreve o ambiente institucional corporativo brasileiro como sendo caracterizado pela concentração de propriedade, inclusive no âmbito das companhias abertas. A pesquisa de Balassiano (2012) demonstra que essa situação não se alterou nos últimos anos, pois o autor verificou que a estrutura de capital acionário das empresas abertas, no ano 2010, era concentrada, com média de $47,9 \%$ e mediana de $51,7 \%$, verificando-se, em vários casos, uma considerável distância entre o poder de voto e o poder do fluxo de caixa dos acionistas majoritários. Silveira (2002) e Balassiano (2012) ressaltam que, consequentemente, os conflitos de agência no Brasil ocorrem mais pelo exercício do benefício privado do controle do que pela expropriação de parcela da riqueza dos acionistas por parte dos gestores. Tal situação funciona como incentivo ao financiamento das empresas pela iniciativa privada (COELHO, LIMA, 2008).

Assim, este estudo pretende responder à seguinte questão de pesquisa: Os resultados contábeis divulgados pelos bancos brasileiros apresentam atributos de conservadorismo condicional? 
O objetivo da pesquisa consiste em buscar evidências que possibilitem identificar se os resultados contábeis reportados pelos bancos apresentam características de conservadorismo condicional. Adicionalmente, será investigado se o grau de conservadorismo identificado apresenta diferenciação quando se comparam os bancos de capital aberto com os de capital fechado. Concentrar-se-á atenção sobre a estrutura de propriedade, assumindo-se como racional a escolha pelos acionistas de uma empresa entre manter o capital aberto ou fechado, dados os seus objetivos e as preferências de risco. Não se pretende aqui testar os determinantes da escolha, mas apenas as previsões acerca das implicações contábeis observáveis nos problemas de agência relacionados à estrutura de propriedade escolhida, com destaque para o conservadorismo condicional.

Esta pesquisa se justifica na medida em que discute a prática do conservadorismo pelos bancos que atuam no país, haja vista a sua relevância para a economia e as características próprias de regulação a que se sujeitam.

Além desta introdução, o artigo aborda no referencial teórico o conservadorismo e as relações entre estrutura de propriedade e a contabilidade. Após o referencial, apresenta-se a metodologia, a análise de resultados e as considerações finais.

\section{REFERENCIAL TEÓRICO}

\subsection{Conservadorismo}

O conservadorismo condicional é geralmente conceituado como um grau de verificação assimétrico exigido no reconhecimento de boas e más notícias (BASU, 1997; BALL, KOTHARI, ROBIN, 2000; WATTS, 2003). A literatura fornece outras terminologias para esse tipo de conservadorismo, como ex-post ou news-dependent. Exemplos de conservadorismo condicional incluem a escolha entre 0 valor de custo ou de mercado para os estoques e o impairment para ativos tangíveis e intangíveis de longo prazo (RYAN, 2006). Outro tipo de conservadorismo é o denominado incondicional (ex-ante ou news-independent), que envolve uma predeterminada subavaliação do valor dos ativos líquidos, e foge ao foco desta pesquisa. Exemplos de conservadorismo incondicional incluem o registro imediato de despesas de custos de ativos intangíveis gerados internamente e a depreciação de ativos de longo prazo numa taxa superior à taxa de depreciação econômica esperada (RYAN, 2006). Para o propósito deste estudo, será adotado o termo conservadorismo condicional (BALL, SHIVAKUMAR, 2005; BEAVER, RYAN, 2005).

A maioria das pesquisas nesse campo acompanha o modelo de reconhecimento oportuno dos ganhos de Basu (1997). Esse autor testou o conservadorismo condicional fazendo uma regressão entre os lucros contábeis anuais e os retornos das ações nos mesmos anos, separando as empresas com retornos negativos e aquelas com retornos positivos, adotando esses retornos como proxy para boas e más notícias. O autor previu e verificou empiricamente um R2 maior para a amostra de retornos negativos (más notícias) do que para a amostra de retornos positivos (boas notícias), implicando uma assimetria de oportunidade (asymmetrictimeliness) de reconhecimento de perdas em relação aos ganhos. Sua amostra compreendeu dados de empresas com títulos negociados na Bolsa de Nova lorque entre 1963 e 1990.

Basu (1997) também mostrou que essa medida de assimetria de oportunidade varia (em média, aumenta) durante o período 1964-1989, consistente com variações crescentes na litigiosidade. Por fim, ele forneceu evidências da presença de três outras implicações para o conservadorismo condicional: a assimetria resulta mais dos accruals do que dos fluxos de caixa, embora ele tenha verificado que fluxos de caixa operacionais também apresentem considerável assimetria de oportunidade; as variações negativas nos lucros são menos persistentes do que as positivas; e, na 
regressão normal de retornos sobre ganhos, o coeficiente dos lucros é mais positivo quando os lucros são positivos do que quando são negativos.

O estudo de Basu (1997) se tornou um dos mais influentes na pesquisa contábil da sua década (RYAN, 2006). Os estudos que seguiram o modelo de Basu (1997) encontraram evidências de que o conservadorismo condicional medido pela assimetria de reconhecimento de perdas e ganhos varia entre as firmas de conformidade com suas características, escolhas e contextos econômicos, de maneira consistente com a magnitude dos incentivos e contratos envolvidos e com a maneira como as firmas abordam essas questões (POPE, WALKER, 1999; BALL, KOTHARI, ROBIN, 2000; WATTS, 2003; BUSHMAN, PIOTROSKI, 2006).

\subsection{Estudos anteriores}

A literatura brasileira especializada em conservadorismo contábil tem crescido nos últimos anos, a partir de diversas abordagens, conforme destaques listados no Quadro 1.

Quadro 1 - Pesquisas de autores brasileiros sobre conservadorismo contábil

\begin{tabular}{|c|c|c|}
\hline Referência & Objetivos/Hipóteses & Resultados \\
\hline Lopes (2001) & $\begin{array}{l}\text { Conservadorismo patrimonial e no } \\
\text { reconhecimento de perdas } \\
\text { econômicas }\end{array}$ & $\begin{array}{l}\text { Detectado conservadorismo } \\
\text { patrimonial ao contrário e baixa } \\
\text { antecipação de perdas }\end{array}$ \\
\hline Costa, Teixeira e Nossa (2002) & $\begin{array}{l}\text { Revisão teórica e de pesquisas sobre } \\
\text { conservadorismo }\end{array}$ & Descrição teórica do assunto \\
\hline Rangel e Teixeira (2003) & $\begin{array}{l}\text { Detecção de conservadorismo através } \\
\text { do índice Preço / Patrimônio Líquido }\end{array}$ & Detectado baixo conservadorismo \\
\hline Costa, Lopes e Costa (2006) & $\begin{array}{l}\text { Conservadorismo entre países da } \\
\text { América do Sul }\end{array}$ & $\begin{array}{l}\text { Detectado baixo nível de } \\
\text { conservadorismo }\end{array}$ \\
\hline Santos e Costa (2008) & $\begin{array}{l}\text { Conservadorismo das empresas } \\
\text { brasileiras com ADRs negociados na } \\
\text { Bolsa de Nova lorque }\end{array}$ & $\begin{array}{l}\text { Não detectadas diferenças no nível } \\
\text { de utilização do conservadorismo }\end{array}$ \\
\hline $\begin{array}{l}\text { Paulo, Antunes e Formigoni } \\
\text { (2006) }\end{array}$ & $\begin{array}{l}\text { Distinção da prática de } \\
\text { conservadorismo entre empresas de } \\
\text { capital aberto e empresas de capital } \\
\text { fechado }\end{array}$ & $\begin{array}{l}\text { Detectado maior conservadorismo } \\
\text { nas empresas de capital aberto }\end{array}$ \\
\hline Coelho e Lima (2008) & $\begin{array}{l}\text { Distinção da prática de } \\
\text { conservadorismo entre empresas de } \\
\text { capital aberto e empresas de capital } \\
\text { fechado }\end{array}$ & $\begin{array}{l}\text { Sem diferença entre os dois } \\
\text { grupos de empresas }\end{array}$ \\
\hline Costa et al. (2009) & $\begin{array}{l}\text { Impacto da regulação no } \\
\text { conservadorismo das empresas } \\
\text { listadas na BM\&FBovespa }\end{array}$ & $\begin{array}{l}\text { Não detectado impacto da } \\
\text { regulação no conservadorismo }\end{array}$ \\
\hline Lima, Fonseca e Brito (2009) & $\begin{array}{l}\text { Conservadorismo nos bancos } \\
\text { portugueses }\end{array}$ & $\begin{array}{l}\text { Não detectado conservadorismo } \\
\text { condicional }\end{array}$ \\
\hline Gonzaga e Costa (2009) & $\begin{array}{l}\text { Conservadorismo e políticas de } \\
\text { dividendos nas empresas listadas na } \\
\text { BM\&FBovespa }\end{array}$ & $\begin{array}{l}\text { Detectado conservadorismo e } \\
\text { conflitos sobre as políticas de } \\
\text { dividendos }\end{array}$ \\
\hline Silva et al. (2009) & $\begin{array}{l}\text { Impacto das agências reguladoras no } \\
\text { nível de conservadorismo condicional } \\
\text { de empresas de capital aberto }\end{array}$ & $\begin{array}{l}\text { A regulação não constitui incentivo } \\
\text { suficiente para adoção do } \\
\text { conservadorismo }\end{array}$ \\
\hline Coelho, Cia e Lima (2010) & Distinção da prática de & Não detectada diferença entre as \\
\hline
\end{tabular}

Revista de Contabilidade e Controladoria, ISSN 1984-6266

Universidade Federal do Paraná, Curitiba, v. 8, n.3, p. 8-27, set./dez. 2016. 


\begin{tabular}{|c|c|c|}
\hline Referência & Objetivos/Hipóteses & Resultados \\
\hline & $\begin{array}{l}\text { conservadorismo entre empresas } \\
\text { emissoras e não emissoras de ADR }\end{array}$ & empresas \\
\hline $\begin{array}{l}\text { Neto, Rodrigues e Almeida } \\
\text { (2010) }\end{array}$ & $\begin{array}{l}\text { Conservadorismo conforme estrutura } \\
\text { de propriedade: concentração de } \\
\text { votos e acordo de acionistas }\end{array}$ & $\begin{array}{l}\text { A concentração de votos diminui } \\
\text { o conservadorismo, enquanto o } \\
\text { acordo de acionistas contribui para } \\
\text { aumentá-lo }\end{array}$ \\
\hline Moreira e Colauto (2010) & $\begin{array}{l}\text { Conservadorismo conforme o nível de } \\
\text { governança da BM\&FBovespa }\end{array}$ & Não detectado conservadorismo \\
\hline Mendonça et al. (2010) & $\begin{array}{l}\text { Impacto da SOX na qualidade do lucro } \\
\text { das empresas brasileiras emissoras de } \\
\text { ADR antes de } 2002\end{array}$ & $\begin{array}{l}\text { Encontradas evidências de } \\
\text { aumento do conservadorismo mas } \\
\text { por outros motivos que não a SOX }\end{array}$ \\
\hline Santos et al. (2011) & $\begin{array}{l}\text { Efeito da Lei n. } 11.638 / 2007 \text { no } \\
\text { conservadorismo das empresas } \\
\text { listadas na BM\&FBovespa }\end{array}$ & $\begin{array}{l}\text { Não detectado impacto no } \\
\text { conservadorismo condicional }\end{array}$ \\
\hline Brito, Lopes e Coelho (2012) & $\begin{array}{l}\text { Distinção entre a prática de } \\
\text { conservadorismo em bancos estatais e } \\
\text { aquela adotada em bancos privados }\end{array}$ & $\begin{array}{l}\text { Detectado maior conservadorismo } \\
\text { nos bancos estatais }\end{array}$ \\
\hline Amaral, Riccio e Sakata (2012) & $\begin{array}{l}\text { Revisão teórica e de pesquisas sobre } \\
\text { conservadorismo }\end{array}$ & $\begin{array}{l}\text { Tendência ao estudo do } \\
\text { conservadorismo condicional }\end{array}$ \\
\hline Garbrecht et al. (2012) & $\begin{array}{l}\text { Impacto da Lei n. } 11.638 / 2007 \text { no } \\
\text { conservadorismo condicional das } \\
\text { empresas listadas na BM\&FBovespa }\end{array}$ & $\begin{array}{l}\text { Detectada redução do } \\
\text { conservadorismo após a edição da } \\
\text { lei }\end{array}$ \\
\hline Filipin et al. (2012) & $\begin{array}{l}\text { Impacto da adoção das IFRS sobre o } \\
\text { conservadorismo condicional das } \\
\text { empresas listadas na BM\&FBovespa }\end{array}$ & $\begin{array}{l}\text { Detectado maior conservadorismo } \\
\text { nas demonstrações contábeis } \\
\text { elaboradas segundo as IFRS do que } \\
\text { naquelas elaboradas sob BR-GAAP }\end{array}$ \\
\hline
\end{tabular}

Fonte: Elaborado pelos autores, com base em Coelho e Lima (2008).

Como se percebe no Quadro 1, embora o interesse pelo conservadorismo tenha se intensificado nos últimos anos, ainda são raros no país estudos examinando a prática do conservadorismo em instituições financeiras. Com efeito, apenas dois associam bancos e conservadorismo (LIMA, FONSECA, BRITO, 2009; BRITO, LOPES, COELHO, 2012) e três associam conservadorismo e estrutura de propriedade (PAULO, ANTUNES, FORMIGONI, 2006; COELHO, LIMA, 2008; NETO, RODRIGUES, ALMEIDA, 2010). Mas nenhum associa bancos, conservadorismo e estrutura de propriedade.

As características relativas à estrutura de propriedade e suas implicações para a contabilidade foram objeto de estudo por autores estrangeiros, como Beatty e Harris (1998), Ball e Shivakumar (2005), LaFond e Roychowdhury (2007), Nichols, Wahlen e Wieland (2009), Boná-Sánchez, PerezAlemán e Santana-Martín (2009) e Ramalingegowda e Yu (2012).

2.3 Estrutura de propriedade e suas implicações para a contabilidade

Os bancos de capital aberto se diferenciam dos bancos de capital fechado basicamente em duas dimensões organizacionais, quais sejam, controle (BEATTY, HARRIS, 1998) e acesso ao mercado de capitais (NICHOLS, WAHLEN, WIELAND, 2009), as quais têm potencialmente importantes implicações nos relatórios financeiros. Para Nichols, Wahlen e Wieland (2009), em tese, a necessidade de controle corporativo é grande nos bancos devido ao seu alto potencial de assimetria informacional, pelo fato de esse tipo de empresa intermediar muitos tipos de risco, como, por exemplo, risco de crédito, risco de taxa de juros, variações da taxa de risco e risco de liquidez. E essa exposição aos 
riscos, embora seja uma resposta ao movimento do mercado - taxa de juros ou de câmbio -, não é facilmente observável pelos acionistas externos.

As diferenças de controle surgem devido à separação entre principal e agente (proprietários e gerentes), sendo mais acentuadas nos bancos de capital aberto. Maior separação resulta em potencial para maior assimetria informacional entre proprietários e gerentes, a qual exacerba o potencial para risco moral e problemas de seleção adversa. Na opinião de Nichols, Wahlen e Wieland (2009), espera-se que os bancos de capital fechado estabeleçam mecanismos explícitos de contratação e monitoramento para alinhar os incentivos entre agentes e principais que reforcem a exigência de prestação de contas.

Segundo Beatty e Harris (1998), além da maior assimetria informacional entre gerentes e investidores, espera-se que os gerentes de empresas abertas estejam mais concentrados nas cotações das ações, bem como nos efeitos do seu gerenciamento. Esses autores ressaltam que a demanda por gerenciamento depende também do volume e da frequência de negociação de ações, bem como da proporção de acionistas administradores.

Nos bancos de capital fechado, em tese, o controle fica restrito a poucos acionistas, sendo tipicamente administrado e operacionalizado pelos acionistas majoritários. Assim, o principal meio de distribuir lucros é via salários, em oposição aos dividendos. Empregados-chave também tendem a concentrar um alto percentual das ações da empresa. Como esses acionistas empregados/administradores sabem diretamente o que deve ser comunicado a eles, a assimetria informacional é reduzida, havendo, assim, menos incentivos para gerenciar resultados. Embora nem todos os acionistas de bancos de capital fechado sejam empregados, e permaneça a necessidade de comunicação indireta, ela deve ser muito menor para as firmas de capital fechado do que para as de capital aberto (BEATTY, HARRIS, 1998; BEATTY, KE, PETRONI, 2002).

Ball e Shivakumar (2005) concordam que as firmas de capital fechado resolvem seu problema de assimetria informacional por meio de um modelo de acesso interno. Segundo os autores, as empresas de capital fechado são menos propensas a usar relatórios financeiros públicos nos contratos com fornecedores, gerentes e outras partes, assim como em transações de capital primárias e secundárias. Seus relatórios financeiros são mais influenciados pela questão fiscal, pela distribuição de resultados e por outras políticas. Essas diferenças também implicam uma demanda menor por mais qualidade do relatório contábil.

Beatty e Harris (1998) destacam, porém, que embora os custos de agência possam ser diferentes nos dois tipos de empresa, os custos de agência em bancos, de capital aberto ou fechado, devem ser menores, por serem sujeitos à mesma revisão regulatória. E, por isso, o gerenciamento de resultados seria similar nos dois tipos de banco.

Na visão de Nichols, Wahlen e Wieland (2009), bancos de capital aberto e de capital fechado são diferentes também em seu acesso ao mercado de capitais. Pelo fato de terem mais acesso a financiamento de capital externo, os bancos de capital aberto tendem a ser maiores, crescer mais rápido e ser mais lucrativos. Os autores afirmam que a separação entre capital aberto e capital fechado afeta dois custos associados ao acesso ao mercado de capitais. Primeiro, as ações de bancos de capital aberto são mais líquidas que as dos bancos de capital fechado, de forma que os investidores demandam um prêmio de liquidez para adquirir ações de empresas de capital fechado, aumentando o custo do capital. Segundo, os bancos de capital aberto podem levantar capital novo, através de transações no mercado aberto, como, por exemplo, a oferta sazonal de ações.

A escolha da estrutura de propriedade sobre o controle e o acesso ao mercado de capitais influencia de maneira compensatória os relatórios financeiros (NICHOLS, WAHLEN, WIELAND, 2009). À medida que aumenta a assimetria informacional entre proprietários e gerentes e cresce o apetite da firma 
por capital de investidores externos (e, com ele, a necessidade de atingir expectativas de lucros), os gerentes têm incentivos e maior habilidade para exercer uma contabilidade que aumente os lucros (anticonservadora). Entretanto, esses mesmos fatores também amplificam a demanda dos acionistas por verificabilidade externa dos relatórios financeiros. Embora conservadorismo e verificabilidade tenham características distintas, são conectados de tal forma que o conservadorismo condicional envolve requerer um padrão mais alto de verificabilidade para reconhecer perdas mais do que ganhos. Para Watts (2003), o conservadorismo sobrevive em equilíbrio porque restringe o oportunismo e o otimismo gerencial e, assim, possibilita a eficiência contratual entre a firma e seus diversos stakeholders. Assim, o conservadorismo condicional tem maior probabilidade de ocorrer em empresas de capital aberto.

Os lucros reportados servem de sinalização para investidores e analistas, e o gerenciamento dos lucros possibilita que os gerentes controlem esses sinais. Os investidores externos dispõem, em tese, de menos informações sobre firmas de capital fechado. Por essa razão, os lucros gerenciados dessas firmas têm relativamente menos importância em termos de sinalização, possivelmente oferecendo às firmas de capital fechado menores incentivos para gerenciar lucros do que às de capital aberto. À luz dessas observações, o conservadorismo contábil pode ser menor em empresas de capital fechado.

Ball e Shivakumar (2005) examinaram a diferença de conservadorismo entre firmas de capital aberto e de capital fechado, constatando que as firmas de capital fechado são menos conservadoras. Eles atribuem essa diferença no conservadorismo às diferentes estruturas de governança e mecanismos de monitoramento entre firmas de capital fechado e de capital aberto. Os autores, no entanto, identificaram muitas diferenças estruturais entre governança e ambiente de contratação na comparação das duas modalidades de firma. O relatório financeiro das empresas de capital fechado é mais conduzido pelos impostos, dividendos e outras políticas, e menos direcionado por preocupações contratuais. Assim, suas evidências não podem ser atribuídas somente a diferenças sistemáticas entre propriedade gerencial e ao conservadorismo.

LaFond e Roychowdhury (2007) encontraram evidências de uma relação sistemática entre propriedade gerencial, medida pela porcentagem de ações pertencentes ao CEO, e conservadorismo. Os autores concluíram que as firmas cujos CEOs possuem menos ações apresentam lucros mais conservadores, corroborando a ideia de que o conservadorismo é um mecanismo potencial para se abordar problemas de agência que surgem da maior separação entre propriedade e controle. Embora a amostra desses autores incluísse apenas firmas de capital aberto, seus achados se aplicam às duas modalidades utilizadas nesta pesquisa em relação à separação entre controle e propriedade.

\section{METODOLOGIA}

Quanto aos objetivos, esta pesquisa se caracteriza como descritiva. Quanto à abordagem do problema, pode ser caracterizada como quantitativa (MARTINS, THEÓPHILO, 2009). A coleta dos dados se deu na modalidade documental, identificada como método para "coleta de documentos de primeira ou segunda mão, ou ainda, dados primários e dados secundários" (MARTINS, THEÓPHILO, 2009 , p. 88). Aqui, representados pelos balanços semestrais dos bancos brasileiros, referentes ao período de junho de 1999 a junho de 2012. Os dados foram extraídos do website do Banco Central, onde são dispostos de acordo com o Plano Contábil das Instituições do Sistema Financeiro Nacional (Cosif). Foram utilizados os valores referentes a lucro líquido e ativo total de todos os bancos da amostra.

Revista de Contabilidade e Controladoria, ISSN 1984-6266 
Embora a partir de dezembro de 2010 as instituições financeiras constituídas sob a forma de companhia aberta fossem obrigadas a elaborar e divulgar demonstrações contábeis consolidadas no padrão contábil internacional (IFRS), os relatórios utilizados nesta pesquisa seguem o padrão estabelecido pelo Banco Central, de forma a garantir a homogeneidade dos dados. O período anterior a 1999 foi desconsiderado, haja vista que nele se refletem, acentuadamente, os efeitos do Programa de Estabilização Econômica de 1994, popularmente conhecido como Plano Real, que gerou alteração estrutural na economia brasileira, com descontinuidade de muitas empresas.

Além dos balanços semestrais, foram utilizadas informações quanto à estrutura de propriedade de cada instituição, obtidas no website da Bolsa de Valores, Mercadorias e Futuros (BM\&FBovespa). Foram coletados dados do período de junho de 1999 a junho de 2012, sendo necessária a consideração de dois semestres a menos, dada a característica defasada de cálculo de alguns dos dados. Assim, foram utilizados dados de 24 semestres (junho de 2000 a junho de 2012).

O foco no setor bancário se justifica pelo fato de esse segmento ser geralmente excluído das pesquisas, mas apresentar disponibilidade para fornecer informações de lucros comparáveis para empresas de capital aberto e de capital fechado (BEATTY, HARRIS, 1998). Informações sobre empresas de capital fechado raramente são disponíveis em setores não financeiros. Além disso, observa-se que a visibilidade política dos bancos é alta, comparada com a de outros segmentos, porquanto os bancos administram sistemas de pagamentos e fornecimento de liquidez, e são instrumentos de política monetária. Todos os governos regulam e supervisionam os bancos para promover um sistema financeiro sólido e seguro; logo, essas instituições operam dentro de um ambiente regulatório sujeito a cuidadoso monitoramento e controle. Os relatórios contábeis dos bancos de capital fechado são interessantes por si sós, devido à sua predominância na economia: $87 \%$ dos bancos são empresas de capital fechado.

O sistema bancário brasileiro reúne 182 bancos (posição em junho de 2012), entre comerciais (22), múltiplos (139), de investimento (15), de desenvolvimento (4) e de câmbio (2). Desses, apenas 23 têm ações negociadas na BM\&FBovespa. Foram excluídas as empresas que não apresentaram dados referentes a todos os períodos da observação. Em consequência, a amostra ficou reduzida a 92 bancos, sendo 79 com capital fechado e 13 com capital aberto. Desse modo, não será possível generalizar os resultados do estudo para toda a população considerada.

O fato de se optar pelo método não probabilístico deve-se à necessidade de se contar com uma série completa de informações, em virtude de uma das variáveis relevantes para a análise ser a variação dos lucros, baseada em série temporal de dados, período a período, além da necessidade de se utilizar dados balanceados para aplicação do modelo com dados em painel.

Apesar da limitação quanto aos aspectos relacionados à generalização, destaca-se que a amostra apresenta tamanho significativo, tomando-se como referência o valor dos ativos dos bancos selecionados, que concentram $86 \%$ dos ativos totais da população de interesse.

Considerando-se o ambiente institucional brasileiro de baixo incentivo à elaboração das demonstrações contábeis com atributos de qualidade informacional, as diferenças de problemas de agência, detectadas pelos estudos anteriores, entre os segmentos aberto e fechado, e também a forte regulação exercida pelo Banco Central, foram estabelecidas as seguintes hipóteses.

H1: os resultados contábeis divulgados pelos bancos brasileiros apresentam características de conservadorismo condicional; e

H2: os resultados contábeis divulgados pelos bancos de capital aberto apresentam maior grau de conservadorismo condicional do que os dos bancos de capital fechado. 


\subsection{Os modelos}

Para atender ao objetivo desta pesquisa, foi utilizado o modelo de Ball e Shivakumar (2005), que tem como referência o modelo original de Basu (1997) que mede a persistência e a transitoriedade dos ganhos e perdas ao segregar as variações positivas das variações negativas na série temporal de retornos (proxy para boas e más notícias), utilizando como variável dependente o lucro contábil. 0 modelo de Ball e Shivakumar (2005) foi adaptado às variáveis contábeis selecionadas dos bancos, e a variação dos lucros no período anterior foi utilizada como proxy para boas e más notícias, sendo utilizado para testar a hipótese $\mathrm{H} 1$ - os resultados contábeis divulgados pelos bancos brasileiros apresentam atributos de conservadorismo condicional -, por meio da seguinte fórmula:

$$
\Delta N I_{i t}=\alpha_{0}+\alpha_{1} D \Delta N I_{i t-1}+\alpha_{2} \Delta N I_{i t-1}+\alpha_{3} D \Delta N I_{i t-1} \times \Delta N I_{i t-1}+c_{i}+\varepsilon_{i t}
$$

em que:

$\Delta N I_{i t}$ é a variação no resultado no semestre t - 1 a t, ponderado pelo valor contábil inicial do total dos ativos;

$D \Delta N I_{i t-1}$ é uma variável dummy que assume o valor 1 se a variação no semestre anterior é negativa, e valor 0 se é positiva;

$\Delta N I_{i t-1}$ é a variação no lucro do banco i do semestre $\mathrm{t}-2$ para o semestre $\mathrm{t}-1$, ponderada pelo valor do ativo total no início do ano $\mathrm{t}-1$;

$D \Delta N I_{i t-1} \times \Delta N I_{i t-1}$ é a variável de interação, que capta os efeitos de variações negativas antecedentes; e

$c_{i}+\varepsilon_{i t}$ é o termo de erro.

O parâmetro $\alpha_{0}$ representa o intercepto, e é inerente ao modelo estatístico, não possuindo significado na análise econômica e teórica. $O$ coeficiente $\alpha_{1}$ é uma variável dummy que mensura a velocidade do reconhecimento do resultado econômico anterior pelo resultado contábil presente. Ele busca verificar se o lucro líquido do momento $t$ é mais sensível aos resultados negativos ou positivos do momento t-1. O sinal esperado para a variável $\alpha_{1}$ é negativo, e valores maiores e mais significativos indicam que a informação contábil é oportunamente transmitida para os resultados.

$\mathrm{O}$ coeficiente $\alpha_{2}$ captura o reconhecimento positivo e negativo, em conjunto do lucro antecedente no lucro atual, refletindo a oportunidade de reconhecimento. O coeficiente com sinal positivo revela uma associação direta entre a variação no lucro contábil no momento t-1 e a sua variação no momento t; variação positiva no lucro reflete variação positiva no lucro; variação negativa no lucro reflete variação negativa no lucro. Observa-se que embora $\alpha_{2}$ seja interpretado como sensibilidade às boas notícias, esse não é o título apropriado, porque, mantidas constantes as demais condições, quando $\alpha_{2}$ é menor, tanto as boas como as más notícias são menos oportunas.

O coeficiente $\alpha_{3}$ informa como as notícias são refletidas no lucro, sendo que um coeficiente elevado indica que os lucros presentes exibem uma resposta maior para um dado montante de notícias nos lucros passados. O coeficiente $\alpha_{3}$ informa se esse reconhecimento é incrementalmente diferente para as más notícias. Quando $\alpha_{3}<0$, as más notícias são refletidas na variação dos lucros $\left(\Delta \mathrm{NI}_{\text {it }}\right)$ mais rapidamente do que as boas notícias, e se considera a contabilidade como sendo conservadora.

Por outro lado, o reconhecimento oportuno das más notícias faz com que as perdas decorrentes sejam componentes transitórios da série temporal de lucros, que são revertidas no período seguinte. Desse modo, espera-se que a soma dos coeficientes $\alpha_{2}$ e $\alpha_{3}$ seja menor que zero $\left(\alpha_{2}+\alpha_{3}<0\right)$. 
Ball e Shivakumar (2005) ampliaram o modelo de Basu (1997), utilizando exclusivamente variáveis contábeis para obter uma medida que explorasse a natureza transitória dos resultados econômicos, diferenciando as companhias entre abertas e fechadas. Os autores incluíram no modelo uma variável binária interativa que discrimina as empresas segundo sua forma societária. Adaptando-se ao objetivo desta pesquisa, essa variável discriminará a forma jurídica do banco. A hipótese a ser testada nesse modelo $(\mathrm{H} 2)$ é que os bancos de capital fechado apresentam comportamento menos conservador do que os bancos de capital aberto, devido à pequena demanda por mais qualidade nos relatórios financeiros. O modelo, também utilizado nos estudos de Coelho e Lima (2008) e Lima, Fonseca e Brito (2009), é assim expresso:

$$
\begin{gathered}
\Delta N I_{i t}=\alpha_{0}+\alpha_{1} D \Delta N I_{i t-1}+\alpha_{2} \Delta N I_{i t-1}+\alpha_{3} D \Delta N I_{i t-1} \times \Delta N I_{t-1}+\alpha_{4} D P R+\alpha_{5} D P R \\
\quad \times D \Delta N I_{i t-1}+\alpha_{6} D P R \times \Delta N I_{i t-1}+\alpha_{7} D P R \times D \Delta N I_{i t-1} \times \Delta N I_{i t-1}+c_{i}+\varepsilon_{i t} \\
\text { em que: }
\end{gathered}
$$

$\Delta N I_{i t}$ é a variação no resultado no semestre $t-1$ a $t$, ponderado pelo valor contábil inicial do total dos ativos;

$D \Delta N I_{i t-1}$ é uma variável dummy que assume o valor 1 se a variação no semestre anterior é negativa, e valor 0 se é positiva;

$\Delta N I_{i t-1}$ é a variação no lucro do banco i do semestre $t-2$ para o semestre $t-1$, ponderada pelo valor do ativo total no início do ano $t-1$;

$D \Delta N I_{i t-1} \times \Delta N I_{i t-1}$ é a variável de interação, que capta os efeitos de variações negativas antecedentes;

$D P R$ é uma variável dummy que assume valor 1 para companhias fechadas, e 0 para companhias abertas;

$D P R \times D \Delta N I_{i t-1}$ é a variável que capta o impacto do intercepto no modelo;

$D P R \times \Delta N I_{i t-1}$ é a variável de interação, que capta o efeito de variações antecedentes para companhias fechadas;

$D P R \times D \Delta N I_{i t-1} \times \Delta N I_{i t-1}$ é a variável discriminatória para os valores referentes às companhias abertas; e

$c_{i}+\varepsilon_{i t}$ é o termo de erro.

O comportamento esperado dos coeficientes $\alpha_{0}, \alpha_{1}, \alpha_{2}$ e $\alpha_{3}$ é o mesmo já descrito. Os coeficientes $\alpha_{4}, \alpha_{5}, \alpha_{6}$ e $\alpha_{7}$ foram incluídos para capturar o comportamento diferenciado entre os dois grupos de bancos. Espera-se que os bancos de capital fechado apresentem menor reconhecimento oportuno das perdas decorrentes das más notícias, comparativamente aos bancos de capital aberto, o que implica que o coeficiente $\alpha_{7}$ seja maior que zero $\left(\alpha_{7}>0\right)$.

Espera-se, também, que o somatório dos coeficientes $\alpha 2, \alpha 3, \alpha 6$ e $\alpha 7$, indicativos de persistência/reversão de componentes do lucro na presença de variações negativas no lucro antecedente dos bancos de capital fechado, tenha valor em módulo maior que o do outro segmento $\left(\alpha_{2}+\alpha_{3}\right)$. Isso indicaria que os bancos de capital fechado têm maior persistência das variações negativas nos resultados, quando comparados aos bancos de capital aberto.

\section{APRESENTAÇÃO DOS DADOS E ANÁLISE DOS RESULTADOS}

A Tabela 1 exibe as estatísticas descritivas do lucro líquido dos bancos participantes da amostra. Para minimizar as diferenças entre os tamanhos dos bancos, o lucro líquido semestral de cada instituição foi dividido pelo respectivo ativo total. A média e a mediana de todos os semestres são $1,01 \%$ e $0,66 \%$, respectivamente. Os dados revelam uma grande amplitude na variável lucro líquido / ativo 
total, entre -32,2\% (observado em junho de 2007) e 36,9\% (junho de 2009). Essas diferenças podem ser atribuídas a aspectos como diversidade de tamanho, tempo de funcionamento e capacidade administrativa de cada banco.

Tabela 1 - Estatísticas descritivas da variável lucro líquido / ativo total

\begin{tabular}{|c|c|c|c|c|c|c|c|c|c|c|c|c|}
\hline \multirow{2}{*}{ Posição } & \multicolumn{4}{|c|}{$\begin{array}{c}\text { Amostra (92) } \\
(\%)\end{array}$} & \multicolumn{4}{|c|}{$\begin{array}{c}\text { Bancos de capital } \\
\text { aberto (13) } \\
(\%)\end{array}$} & \multicolumn{4}{|c|}{$\begin{array}{c}\text { Bancos de capital } \\
\text { fechado (79) } \\
(\%)\end{array}$} \\
\hline & Média & Mediana & Mínimo & Máximo & Média & Mediana & Mínimo & Máximo & Média & Mediana & Mínimo & Máximo \\
\hline Dez./1999 & 0,6 & 0,5 & $-8,3$ & 9,1 & 1,3 & 0,4 & $-0,2$ & 8,2 & 0,5 & 0,6 & $-8,3$ & 9,1 \\
\hline Jun./2000 & 1,2 & 0,8 & $-3,5$ & 11,0 & 1,2 & 0,6 & $-2,0$ & 7,5 & 1,2 & 0,9 & $-3,5$ & 11,0 \\
\hline Dez./2000 & 0,9 & 0,7 & $-5,2$ & 7,2 & 1,0 & 0,5 & $-0,1$ & 4,1 & 0,9 & 0,8 & $-5,2$ & 7,2 \\
\hline Jun./2001 & 1,2 & 1,0 & $-4,6$ & 7,4 & 0,6 & 0,5 & $-1,5$ & 2,6 & 1,3 & 1,1 & $-4,6$ & 7,4 \\
\hline Dez./2001 & 1,1 & 0,6 & $-9,8$ & 15,5 & 2,0 & 0,7 & 0,0 & 15,5 & 1,0 & 0,6 & $-9,8$ & 13,5 \\
\hline Jun./2002 & 1,3 & 1,0 & $-8,8$ & 10,7 & 0,2 & 0,7 & $-8,8$ & 3,7 & 1,5 & 1,1 & $-7,7$ & 10,7 \\
\hline Dez./2002 & 0,8 & 0,8 & $-14,7$ & 12,8 & $-0,4$ & 0,5 & $-7,8$ & 1,6 & 1,0 & 0,9 & $-14,7$ & 12,8 \\
\hline Jun./2003 & 0,7 & 0,9 & $-20,6$ & 10,2 & 1,3 & 0,5 & 0,1 & 10,2 & 0,7 & 0,9 & $-20,6$ & 8,4 \\
\hline Dez./2003 & 0,9 & 0,7 & $-15,1$ & 10,6 & 0,7 & 0,5 & $-2,2$ & 2,4 & 0,9 & 0,8 & $-15,1$ & 10,6 \\
\hline Jun./2004 & 1,0 & 0,6 & $-21,9$ & 12,3 & 1,2 & 0,4 & 0,2 & 10,0 & 1,0 & 0,7 & $-21,9$ & 12,3 \\
\hline Dez./2004 & 0,7 & 0,5 & $-6,4$ & 13,7 & 1,6 & 0,7 & $-2,0$ & 13,7 & 0,6 & 0,5 & $-6,4$ & 9,5 \\
\hline Jun./2005 & 1,0 & 0,6 & $-4,5$ & 11,6 & 1,5 & 0,6 & 0,1 & 10,5 & 0,9 & 0,6 & $-4,5$ & 11,6 \\
\hline Dez./2005 & 0,7 & 0,6 & $-26,5$ & 14,0 & 1,4 & 0,6 & 0,2 & 9,4 & 0,6 & 0,6 & $-26,5$ & 14,0 \\
\hline Jun./2006 & 1,3 & 0,8 & $-12,2$ & 14,4 & 2,1 & 0,9 & 0,3 & 13,7 & 1,1 & 0,7 & $-12,2$ & 14,4 \\
\hline Dez./2006 & 1,1 & 0,8 & $-17,3$ & 14,3 & 1,4 & 0,8 & 0,3 & 7,5 & 1,1 & 0,8 & $-17,3$ & 14,3 \\
\hline Jun./2007 & 1,7 & 0,9 & $-32,2$ & 31,9 & 2,3 & 1,1 & 0,1 & 11,7 & 1,6 & 0,9 & $-32,2$ & 31,9 \\
\hline Dez./2007 & 1,6 & 0,9 & $-12,4$ & 13,5 & 2,1 & 1,1 & 0,2 & 11,9 & 1,5 & 0,8 & $-12,4$ & 13,5 \\
\hline Jun./2008 & 1,3 & 0,8 & $-6,7$ & 23,8 & 1,5 & 0,9 & 0,3 & 6,2 & 1,2 & 0,8 & $-6,7$ & 23,8 \\
\hline Dez./2008 & 0,9 & 0,3 & $-13,8$ & 34,9 & 2,6 & 0,8 & 0,1 & 26,0 & 0,7 & 0,2 & $-13,8$ & 34,9 \\
\hline Jun./2009 & 1,3 & 0,4 & $-10,3$ & 36,9 & 0,7 & 0,6 & 0,1 & 3,0 & 1,3 & 0,3 & $-10,3$ & 36,9 \\
\hline Dez./2009 & 1,2 & 0,7 & $-6,7$ & 21,4 & 0,8 & 0,8 & $-0,7$ & 3,1 & 1,3 & 0,6 & $-6,7$ & 21,4 \\
\hline Jun./2010 & 1,2 & 0,6 & $-5,0$ & 12,9 & 0,8 & 0,6 & $-0,1$ & 4,2 & 1,3 & 0,6 & $-5,0$ & 12,9 \\
\hline Dez./2010 & 0,7 & 0,5 & $-6,5$ & 9,4 & 0,6 & 0,8 & $-3,3$ & 4,4 & 0,7 & 0,5 & $-6,5$ & 9,4 \\
\hline Jun./2011 & 0,7 & 0,5 & $-9,0$ & 22,3 & 0,7 & 0,6 & $-1,3$ & 4,5 & 0,7 & 0,5 & $-9,0$ & 22,3 \\
\hline Dez./2011 & 0,5 & 0,3 & $-12,1$ & 8,6 & 0,7 & 0,3 & $-0,3$ & 4,7 & 0,4 & 0,3 & $-12,1$ & 8,6 \\
\hline Jun./2012 & 0,5 & 0,4 & $-7,1$ & 9,9 & 0,4 & 0,4 & $-2,4$ & 3,5 & 0,5 & 0,4 & $-7,1$ & 9,9 \\
\hline Média & 1,0 & 0,7 & & & 1,2 & & & & 1,0 & & & \\
\hline
\end{tabular}

Fonte: Elaborado pelos autores.

Interessante observar que os dois valores extremos da amostra foram registrados no grupo dos bancos de capital fechado. Os valores extremos do grupo de bancos de capital aberto são $-8,8 \%$ em 
junho de 2002 e $26,0 \%$ em dezembro de 2008 . O grupo de bancos de capital aberto assinala um índice ligeiramente superior ao dos bancos de capital fechado: 1,2\% contra 1,0\%. Essa constatação corrobora o entendimento de Nichols, Wahlen e Wieland (2009) de que os bancos de capital aberto tendem a ser mais lucrativos.

Para testar as hipóteses da pesquisa, os coeficientes dos modelos econométricos foram estimados por meio da análise de dados em painel, que combina dados em corte transversal e em série de tempo, na qual se escolhe entre a abordagem de modelo pooled, efeitos fixos e efeitos aleatórios. Decidiu-se pelo método de efeitos fixos, baseado nos resultados obtidos com os testes de Hausman, e também porque esse método considera que as características não observadas de cada empresa são correlacionadas com as variáveis explicativas em qualquer período de tempo. Essa é uma consideração importante, dada a impossibilidade de construção de um modelo que contenha todas as características individuais capazes de afetar a análise da variação do lucro das empresas da amostra.

O poder explicativo dos modelos acompanha os resultados de Ball e Shivakumar (2005), Coelho e Lima (2008) e Lima, Fonseca e Brito (2009), com baixo coeficiente de determinação (10\%). Quanto às demais características dos pressupostos e técnicas econométricas, foi observada a presença de autocorrelação serial e heterocedasticidade dos resíduos, devidamente tratadas. A normalidade dos resíduos é admitida pelo tamanho da amostra, que, pelo Teorema do Limite Central, garante que sua distribuição tenderá à normalidade.

A Tabela 2 exibe os resultados da aplicação do modelo de Ball e Shivakumar (2005) à amostra da pesquisa, com um nível de significância de $5 \%$, apurado por meio do uso do software Stata ${ }^{\circledR}$ v. 11 . Procedeu-se à análise a partir da amostra, seguindo-se a análise do grupo de bancos de capital aberto e do grupo de bancos de capital fechado, com o objetivo de se identificar se os lucros contábeis de cada grupo de instituições, isoladamente, apresentavam características de conservadorismo condicional.

Tabela 2 - Resultados da regressão

\begin{tabular}{|c|c|c|c|c|c|c|}
\hline \multirow[b]{3}{*}{ Lucro líquido } & \multirow{2}{*}{\multicolumn{2}{|c|}{$\begin{array}{c}\alpha_{0}+\alpha_{1} D \Delta N I_{i t-1}+\alpha_{2} \Delta \\
\text { Amostra (92) }\end{array}$}} & \multirow{2}{*}{\multicolumn{2}{|c|}{$\frac{V I_{i t-1}+\alpha_{3} D \Delta N I_{i t-1} \times \Delta}{\text { Bancos de capital }}=$}} & \multirow{2}{*}{\multicolumn{2}{|c|}{$\begin{array}{l}I_{t-1} \\
\text { Bancos de capital aberto } \\
\text { (13) }\end{array}$}} \\
\hline & & & & & & \\
\hline & Coeficiente & P-valor & Coeficiente & P-valor & Coeficiente & P-valor \\
\hline Intercepto $\left(\alpha_{0}\right)$ & $-0,0001311$ & 0,888 & $-0,0015647$ & 0,121 & 0,0009481 & $0,071(* * *)$ \\
\hline$D \Delta N I_{i t-1}\left(\alpha_{1}\right)$ & 0,003502 & $0,028(* *)$ & 0,006106 & $0,000(*)$ & 0,0002333 & 0,559 \\
\hline$\Delta N I_{i t-1}\left(\alpha_{2}\right)$ & $-0,3223947$ & $0,000(*)$ & $-0,2514119$ & $0,000(*)$ & $-0,6024314$ & $0,000(*)$ \\
\hline$D \Delta N I_{i t-1} \times \Delta N I_{t-1}\left(\alpha_{3}\right)$ & 0,0987854 & $0,000(*)$ & 0,0826882 & $0,014(* *)$ & 0,1056335 & 0,294 \\
\hline$\alpha_{2}+\alpha_{3}$ & $-0,31889$ & & $-0,245306$ & & $-0,6022$ & \\
\hline Observações & 2.208 & & 1.896 & & 312 & \\
\hline
\end{tabular}

Na Tabela 2, observa-se que o coeficiente $\alpha_{2}<0$, obtido tanto para a amostra, quanto para cada um dos dois grupos de bancos, apresenta significância estatística no modelo. Esse resultado não revela, como esperado, um caráter permanente das variações positivas dos lucros. $\mathrm{O}$ sinal negativo indica uma associação inversa entre a variação no lucro antecedente positivo e a variação no lucro subsequente positivo, no sentido de reversão (transitoriedade) dos resultados, sendo maior nos bancos de capital aberto (60\%) do que nos bancos de capital fechado (25\%). 
O coeficiente $\alpha_{3}$, que reflete o reconhecimento assimétrico das boas e das más notícias, é estatisticamente significante para a amostra e para o grupo dos bancos de capital fechado, indicando diferença no reconhecimento das boas e das más notícias nos resultados dos bancos pesquisados. Entretanto, o sinal apresentou-se contrário ao esperado, indicando que os ganhos são reconhecidos mais oportunamente do que as perdas. A significância estatística e o sinal positivo encontrados não revelam um comportamento conservador, em que as más notícias são incorporadas nos resultados mais rapidamente do que as boas notícias. Os somatórios dos coeficientes $\alpha_{2}$ e $\alpha_{3}$ para a amostra, para o grupo dos bancos de capital fechado e para o dos bancos de capital aberto são, respectivamente, $-0,31889,-0,245306$ e $-0,6022$. Como em todos os casos a soma resultou negativa, apresenta evidências de reconhecimento oportuno das perdas. Entretanto, somente para a amostra e para o grupo dos bancos de capital fechado esse resultado se revelou estatisticamente significante. Ressalta-se, no entanto, as limitações metodológicas quanto ao emprego de um modelo estatístico que, apesar de ser utilizado por vários autores, pode não ser adequado à realidade brasileira.

Esses resultados indicam que as perdas são reconhecidas oportunamente, porém, para que esse comportamento venha a ser considerado conservador, os ganhos deveriam ser persistentes, o que não foi detectado. $O$ que se verifica é que tanto os ganhos quanto as perdas são reconhecidos oportunamente, sendo a persistência de reconhecimento das perdas um pouco maior que a dos ganhos.

$\mathrm{Na}$ análise baseada na comparação entre os resultados encontrados para o grupo dos bancos de capital aberto e para o grupo dos bancos de capital fechado, especificamente no tocante ao somatório dos coeficientes $\alpha_{2}$ e $\alpha_{3}$, não se pode afirmar que a diferença entre os dois grupos é significativamente diferente. Por esse modelo não foi possível concluir pela existência de diferença de comportamento na comparação entre os dois grupos de bancos. Para investigar essa diferença, de acordo com a segunda hipótese da pesquisa $(\mathrm{H} 2)$, foi utilizado o modelo ampliado de Ball e Shivakumar (2005).

A Tabela 3 exibe os resultados da aplicação do modelo de Ball e Shivakumar (2005) aos dois grupos de bancos da amostra.

Tabela 3 - Resultado da regressão com distinção entre capital aberto e capital fechado

\begin{tabular}{|c|c|c|}
\hline \multicolumn{3}{|c|}{$\begin{aligned} \Delta N I_{i t}= & \alpha_{0}+\alpha_{1} D \Delta N I_{i t-1}+\alpha_{2} \Delta N I_{i t-1}+\alpha_{3} D \Delta N I_{i t-1} \times \Delta N I_{t-1}+\alpha_{4} D P R+\alpha_{5} D P R \\
& \times D \Delta N I_{i t-1}+\alpha_{6} D P R \times \Delta N I_{i t-1}+\alpha_{7} D P R \times D \Delta N I_{i t-1} \times \Delta N I_{i t-1}+\varepsilon_{i t}\end{aligned}$} \\
\hline Lucro líquido & Coeficiente & P-valor \\
\hline Intercepto & $-0,0023$ & 0,667 \\
\hline$D \Delta N I_{i t-1}$ & 0,0054 & 0,484 \\
\hline$\Delta N I_{i t-1}$ & $-0,5349$ & $0,000\left(^{*}\right)$ \\
\hline$D \Delta N I_{i t-1} \times \Delta N I_{t-1}$ & 0,1419 & 0,125 \\
\hline$D P R$ & 0,0017 & 0,755 \\
\hline$D P R \times D \Delta N I_{i t-1}$ & $-0,0007$ & 0,923 \\
\hline$D P R \times \Delta N I_{i t-1}$ & 0,2288 & $0,000\left(^{*}\right)$ \\
\hline$D P R \times D \Delta N I_{i t-1} \times \Delta N I_{i t-1}\left(\alpha_{7}\right)$ & $-0,0364$ & 0,710 \\
\hline$\alpha_{2}+\alpha_{3}$ & $-0,3929$ & \\
\hline$\alpha_{2}+\alpha_{6}$ & $-0,3061$ & \\
\hline$\alpha_{2}+\alpha_{3}+\alpha_{6}+\alpha_{7}$ & $-0,2005$ & \\
\hline Observações & 2.208 & \\
\hline
\end{tabular}

$\left({ }^{*}\right)$ Estatisticamente significante a $1 \%$.

Fonte: Elaborado pelos autores

Para que houvesse reconhecimento diferenciado dos ganhos econômicos, como um componente positivo persistente do lucro, o coeficiente $\alpha_{2}$ seria maior que zero. $O$ valor do coeficiente $\alpha_{2}$ (0,5349 ) contraria o esperado e indica que as variações positivas do lucro são transitórias, 
corroborando o resultado do modelo anterior. Em uma contabilidade conservadora, espera-se que os ganhos econômicos futuros, procedentes dos fluxos de caixa positivos, não sejam reconhecidos no mesmo momento, implicando persistência dos fluxos de caixa do período de forma persistente e positivamente correlacionados com os fluxos de caixa futuros, o que não ocorreu na amostra analisada. Ao contrário, os resultados positivos são revertidos nos períodos subsequentes. Da mesma maneira, os resultados negativos são revertidos nos anos posteriores ao do seu reconhecimento oportuno, pois o somatório dos coeficientes $\alpha 2$,e $\alpha 3(-0,3929)$ é negativo.

Previa-se também que as perdas fossem reconhecidas de forma tempestiva e assimétrica como reduções transitórias do lucro, o que implicaria $\alpha_{3}<0$ e $\alpha_{2}+\alpha_{3}<0$. O coeficiente $\alpha_{3}$, porém, não é estatisticamente significante para a amostra, evidenciando que não há diferença no reconhecimento das boas e das más notícias nos resultados dos bancos. Também se observa que o somatório dos coeficientes $\alpha 1, \alpha 2, \alpha 3$ e $\alpha 4$, indicativos de persistência/reversão de componentes do lucro na presença de variações negativas no lucro antecedente dos bancos de capital fechado, tem valor em módulo maior que o do segmento $\alpha_{2}+\alpha_{3}$. Isso significa que os resultados do grupo dos bancos de capital fechado registram maior persistência das variações negativas do que os dos bancos de capital aberto. Os bancos de capital aberto tendem a reverter em torno de $39 \%$ dos resultados negativos, enquanto os de capital fechado tendem a reverter $20 \%$ dos lucros que sofreram variações negativas.

Quando a variação do lucro antecedente é positiva (coeficientes $\alpha_{2}$ e $\alpha_{6}$ ) com significância estatística, a reversão de componentes transitórios implica comportamento não esperado no modelo, o qual espera coeficientes próximos a zero, o que significa a antecipação de ganhos nessas situações. Já os bancos de capital fechado (coeficientes $\alpha_{2}$ e $\alpha_{6}$ ) parecem antecipar ganhos, o que caracterizaria comportamento oportunista dos gestores.

Espera-se, ainda, que os bancos de capital fechado tenham comportamento diferenciado do dos bancos de capital aberto. Os bancos de capital fechado seriam menos propensos a reconhecer perdas econômicas de forma tempestiva e assimétrica do que ganhos, implicando $\alpha_{7}>0$. Porém, não se confirmam indícios de apropriação assimétrica de perdas econômicas, objeto da segunda hipótese de pesquisa deste estudo, já que os coeficientes $\alpha_{3}$ e $\alpha_{7}$, referentes às variações de interação diferenciadoras do sinal nas variações do lucro antecedente, não exibem significância estatística. Tal resultado sugere que os bancos de capital aberto e os de capital fechado não apresentam diferenças significativas no reconhecimento oportuno das perdas contábeis. Os dois grupos apresentam reversão de componentes, tanto de ganhos quanto de perdas, de forma similar. Como os resultados apresentados não oferecem distinção entre os dois grupos de bancos, estes podem estar relacionados aos interesses existentes entre gestores e proprietários que tendem a ser iguais tanto em banco de capital aberto quanto de capital fechado.

Considerando as evidências, não é possível deixar de rejeitar a primeira hipótese, de que os bancos que atuam no país têm comportamento conservador, conforme definido por Basu (1997), pois se verificou reconhecimento oportuno tanto de perdas quanto de ganhos. Deve-se rejeitar também a hipótese de comportamento diferenciado entre os dois grupos. Destaca-se apenas que a intensidade de reconhecimento de perdas é maior no grupo dos bancos de capital aberto, o que não necessariamente implica um comportamento conservador.

Os resultados desta pesquisa divergem das evidências encontradas nos estudos de Ball e Shivakumar (2005) e Nichols, Wahlen e Wieland (2009), mas estão de acordo com os de Coelho e Lima (2008) e Lima, Fonseca e Brito (2009). Estes últimos também não detectaram conservadorismo condicional nas empresas analisadas, nem diferenciação entre o segmento de capital aberto e o de capital fechado. 


\section{${ }_{5}$ CONSIDERAÇÕES FINAIS}

O presente estudo investigou a prática do conservadorismo condicional nos resultados contábeis dos bancos brasileiros. O modelo de reversão de componentes transitórios do lucro, proposto por Ball e Shivakumar (2005), foi aplicado aos resultados contábeis semestrais de 92 bancos, do período de 1999 a 2012, utilizando a abordagem econométrica da análise de dados em painel.

A análise dos resultados não revelou indícios de conservadorismo condicional nos lucros das empresas analisadas, o que levou à rejeição da primeira hipótese de pesquisa. Os lucros contábeis dos bancos de capital aberto não apresentaram grau de conservadorismo condicional superior àquele registrado pelos bancos de capital fechado, levando também à rejeição da segunda hipótese de pesquisa. Esses resultados corroboram os achados dos estudos de Coelho e Lima (2008) e Lima, Fonseca e Brito (2009).

Essas evidências refletem as características do ambiente institucional brasileiro, cujo modelo legal baseado em regras (code-law) influencia a estrutura de propriedade das empresas e, consequentemente, a demanda por informações contábeis. Isso pode ser verificado, em tese, pelos resultados obtidos por estudos sobre conservadorismo no Brasil listados no Quadro 1, cuja maioria conclui pela não identificação de conservadorismo condicional. Nesse sentido, não se observa uma demanda do mercado brasileiro pelo atributo do conservadorismo condicional como sinal de qualidade informacional dos lucros reportados. No entanto, ressalta-se que o modelo estatístico utilizado neste estudo, apesar de amplamente utilizado por diversos autores, inclusive no contexto nacional, pode não representar a realidade brasileira.

Outra limitação do estudo refere-se ao número de bancos em cada grupo, considerado insuficiente para fornecer amostras homogêneas. Dessa forma, surgem problemas econométricos na construção de grupos com diferentes tamanhos. Ressalte-se também que o modelo examina a presença de componentes transitórios no lucro, e tal transitoriedade pode se dever a movimentos operacionais, de competência contábil ou de caixa, não relacionados à antecipação do registro de perdas (COELHO, LIMA, 2008). De fato, o modelo possibilitou verificar que na presença de variações positivas e negativas dos lucros se evidenciaram reversões dos sinais das variáveis, não se segregando tal movimento especificamente na presença de más notícias.

A semelhança entre o comportamento dos bancos de capital aberto e os de capital fechado pode ser explicada no contexto brasileiro, onde se observa uma estrutura de propriedade e controle bastante concentrada nas empresas de capital aberto (BALASSIANO, 2012), semelhante à propriedade das empresas de capital fechado, que geralmente têm um pequeno número de acionistas, os quais participam do gerenciamento, direcionamento e operações. Além das características institucionais e contratuais, os dois grupos de bancos estão sujeitos ao mesmo ambiente regulatório, não se identificando diferenças fundamentais na demanda por informação pública de qualidade no segmento de bancos de capital aberto.

Como as variações nos lucros são medidas altamente agregadas, os resultados não fornecem percepções sobre a maneira como surge o conservadorismo, conforme ressaltado no estudo de Ryan (2006). Para isso, pesquisas futuras poderiam examinar o papel das provisões para perdas e o risco de crédito, os quais refletem a atividade central dos bancos. Embora sejam reguladas por normas, envolvem um substancial grau de estimação e julgamento por parte dos gerentes, e assim podem criar grande assimetria informacional entre proprietários e gerentes.

Em sentido amplo, procura-se contribuir para o entendimento sobre o comportamento da informação contábil dos bancos e seu papel de intermediação informacional para subsidiar decisões de analistas de mercado e de atuais e potenciais investidores. 


\section{REFERENNCIAS}

ALDRIGHI, D. M.; MAZZER NETO, R. Evidências sobre as estruturas de propriedade de capital e de voto das empresas de capital aberto no Brasil. Revista Brasileira de Economia, v. 61, n. 2, p. 129-152, abr./jul. 2007.

AMARAL, J. V.; RICCIO E. L.; SAKATA, M. C. G. Conservadorismo contábil ainda é discutido? Revista Universo Contábil, Blumenau, v. 8, n. 1, p. 70-85, jan./mar. 2012.

BALASSIANO, M. G. Estrutura de propriedade e teoria da agência: um estudo de empresas brasileiras e seus diferentes tipos de controladores. 2012. 79 f. Dissertação (Mestrado em Administração) Escola Brasileira de Administração Pública e de Empresas, Centro de Formação Acadêmica e Pesquisa, Rio de Janeiro.

BALL, R.; SHIVAKUMAR, L. Earnings quality in UK private firms: comparative loss recognition timeliness. Journal of Accounting \& Economics, v. 39, p. 83-128, 2005.

Therole of accruals in asymmetrically timely gain and loss recognition. Journal of Accounting Research, v.11, i.2, p.207-242, 2006.

; KOTHARI, S. P.; ROBIN, A. The effect of international institutional factors on properties of accounting earnings. (Working Paper FR 99-12) University of Rochester, 2000. Disponível em: $<$ http://ssrn.com/abstract=176989 $>$. Acesso em: 22 dez. 2012.

BASU, S. The conservatism principle and the asymmetric timeliness of earnings. Journal of Accounting and Economics, v. 24, p. 3-37, 1997.

BEAVER, W.; RYAN, S. Conditional and unconditional conservatism: concepts and modeling. Review of Accounting Studies, New York, v. 10, p. 269-309, 2005.

BEATTY, A.; HARRIS, D. G. The effects of taxes, agency costs and information asymmetry on earnings management: a comparison of public and private firms. Review of Accounting Studies, v. 3, p. 299328, 1998.

; KE, B.; PETRONI, K. R. Earnings management to avoid earnings decline across publicly and privately held banks. Accounting Review, n. 77, v. 3, p. 547, jul. 2002.

BEUREN, I. M (Org.). Como elaborar trabalhos monográficos em contabilidade: teoria e prática. 3. ed. São Paulo: Atlas, 2010.

BONÁ-SÁNCHEZ, C.; PEREZ-ALEMÁN, J.; SANTANA-MARTíN, D. J. Ultimate ownership and earnings conservatism. European Accounting Review, p. 1.468-1.497, 2009.

Disponível em: <http://ssrn.com/abstract=1440694>. Acesso em: 22 dez. 2012.

BRITO, G. A. S.; LOPES, A. B.; COELHO, A. C. D. Conservadorismo nos lucros contábeis dos bancos no Brasil: a influência do controle estatal. Revista Universo Contábil, Furb, Blumenau, v. 8, n. 4, p. 19-39, out./dez. 2012. 
BUSHMAN, Robert; PIOTROSKI, J. D. Financial reporting incentives for conservative accounting: the influence of legal and political institutions. Journal of Accounting and Economics, v. 42, i. 1-2, p. 107148. out. 2006. Disponível em: $<$ http://www.sciencedirect.com/science/article/pii/s0165410106000255 $>$. Acesso em: $22 \mathrm{dez}$. 2012.

COELHO, A. C. D.; LIMA, I. S. Conservadorismo nos resultados contábeis publicados no Brasil: comparação entre companhias de capital fechado e companhias de capital aberto. Revista Universo Contábil, v. 4, n. 2, p. 22-41, abr./jun. 2008.

; CIA, J. N. S. Conservadorismo condicional na divulgação de lucros em companhias abertas brasileiras: diferenças entre emissoras e não emissoras de ADRs e entre sistemas contábeis. Revista de Administração Mackenzie, v. 11, n. 1, p. 117-149, jan./fev. 2010.

COSTA, F. M.; LOPES, A. B.; COSTA, A. C. O. Conservadorismo em Cinco Países da América do Sul. Revista de Contabilidade \& Finanças, São Paulo, v. 17, n. 41, p. 7-20, maio/ago. 2006.

COSTA, A. C. O.; TEIXEIRA, A. J. C.; NOSSA, V. Conservadorismo, Accruals e Qualidade dos Lucros Contábeis. In: ENCONTRO DA ASSOCIAÇÃO NACIONAL DE PÓS-GRADUAÇÃO E PESQUISA EM ADMINISTRAÇÃO - ENANPAD, 26, 2002, Salvador. Anais... Salvador: Anpad, 2002. CD-ROM.

COSTA, R. A. et al. O impacto da regulação no conservadorismo das empresas brasileiras listadas na BM\&FBovespa. Contabilidade, Gestão e Governança, Brasília, v. 12, n. 3, p. 28-37, set./dez. 2009.

FILIPIN, R. et al. Análise do nível de conservadorismo condicional das empresas brasileiras listadas na BM\&FBovespa após a adoção das IFRS. Revista de Contabilidade e Controladoria, Universidade Federal do Paraná, Curitiba, v. 4., n. 2, p. 24-26, maio/ago. 2012.

GARBRECHT, G. T. et al. Conservadorismo condicional ex post a Lei 11.638/07: um estudo sobre a qualidade do lucro contábil em empresas listadas na BM\&FBovespa. In: CONGRESSO USP DE CONTROLADORIA E CONTABILIDADE, 12., 2012, São Paulo. Anais... São Paulo: USP, 2012.

GONZAGA, R. P.; COSTA, F. M. A relação entre o conservadorismo contábil e os conflitos entre acionistas controladores e minoritários sobre as políticas de dividendos nas empresas listadas na Bovespa. Revista Contabilidade \& Finanças, USP, São Paulo, v. 20, n. 50, p. 95-109, maio/ago. 2009.

GOTTI, G. Conditional conservatism in accounting: new measure and tests of determinants. Working Paper. University of Massachusetts at Boston - Department of Accounting and Finance, 2008. Disponível em: $<$ http://papers.ssrn.com/sol3/papers.cfm?abstract id=1105083> $>$. Acesso em: $22 \mathrm{dez}$. 2012.

HOLTHAUSEN, R. W.; WATTS, R. S. The relevance of the value-relevance literature for financial accounting standard setting. Journal of Accounting and Economics, n. 31, 2001.

LAFOND, R.; ROYCHOWDHURY, S. Managerial ownership and accounting conservatism. Working Paper, M. I. T., 2007. Disponível em: <http://ssrn.com/abstract=929693 >. Acesso em: 22 dez. 2012.

; WATTS, R. S. The information role of conservatism. The Accounting Review, v. 83, n. 2., 2008. 
LIMA, G. A. S. F.; FONSECA, J. A. S.; BRITO, G. A. S. Conservadorismo nos resultados contábeis dos bancos em Portugal. In: Congresso USP de Controladoria e Contabilidade, 9., 2009, São Paulo. Anais... São Paulo: FEA/USP, 2009. CD-ROM.

LOPES, A. B. Uma Contribuição ao Estudo da Relevância da Informação Contábil para o Mercado de Capitais: o Modelo de Ohlson Aplicado à BOVESPA. 2001. Tese (Doutorado em Controladoria e Contabilidade) - Departamento de Contabilidade e Atuária, Faculdade de Economia, Administração e Contabilidade, Universidade de São Paulo, São Paulo.

MARTINS, G. A.; THEÓPHILO, C. R. Metodologia da investigação cientifica para ciências sociais aplicadas. São Paulo: Editora Atlas, 2009.

MENDONÇA, M. M. et al. O impacto da Lei Sarbanes-Oxley (SOX) no conservadorismo contábil das empresas brasileiras que emitiram ADR antes de 2002: uma investigação usando dados em painel. Revista Contabilidade \& Finanças, USP, São Paulo, v. 21, n. 52, jan./abr. 2010.

MOREIRA, R. L.; COLAUTO, R. D. Conservadorismo condicional: estudo a partir do reconhecimento antecipado de perdas econômicas no resultado. Revista Contabilidade Vista \& Revista, UFMG, Belo Horizonte, v. 21, n. 4, p. 157-187, out./dez. 2010.

NETO, A. S.; RODRIGUES, A.; ALMEIDA, J. E. F. D. Concentração de votos e acordo de acionistas: influências sobre o conservadorismo. Revista Contabilidade \& Finanças, v. 21, n. 54, p. 6-22, 2010.

NICHOLS, D. C.; WAHLEN, J. M.; WIELAND, M. M. Publicly traded versus privately held: implications for conditional conservatism in bank accounting. Review of Accounting

Studies, v. 14, n. 1, p.88-122, 2009.

PAULO, E.; ANTUNES, M. T. P.; FORMIGONI, H. Estudo sobre o conservadorismo nas companhias abertas e fechadas brasileiras. In: ENCONTRO DA ASSOCIAÇÃO NACIONAL DE PÓS-GRADUAÇÃO E PESQUISA EM ADMINISTRAÇÃO - ENANPAD, 30, 2006, Salvador. Anais... Salvador: Anpad, 2006. CDROM.

POPE, P. F.; WALKER, M. International differences in the timeliness, conservatism e classification of earnings. Journal of Accounting Research. Supplement to v. 37, p. 53-87, 1999.

RAMALINGEGOWDA, S.; YU, Y. Institutional ownership and conservatism. Journal of Accounting and Economics, n. 53, p. 98-114, 2012.

RANGEL, L. L.; TEIXEIRA, A. J. C. O conservadorismo contábil e o valor de mercado. In: In: ENCONTRO DA ASSOCIAÇÃO NACIONAL DE PÓS-GRADUAÇÃO E PESQUISA EM ADMINISTRAÇÃO - ENANPAD, 27, Anais... Curitiba: Anpad, 2003. CD-ROM.

RYAN, S. G. Identifying conditional conservatism. European Accounting Review, v. 15, n. 4, p. 511525, 2006.

SANTOS, L. S. R.; COSTA, F. M. Conservadorismo contábil e timeliness: evidências empíricas nas demonstrações contábeis de empresas brasileiras com ADRs negociados na bolsa de Nova lorque. Revista de Contabilidade \& Finanças, v. 19, n. 48, p. 27-36, set./dez. 2008. 
SANTOS, L. P. G. et al. Efeito da lei $11.638 / 07$ sobre o conservadorismo condicional das empresas listadas na BM\&FBovespa. Revista de Contabilidade \& Finanças, São Paulo, v. 22, n. 56, p. 174-188, maio/jun./jul./ago. 2011.

SARTORELLI, I. C.; MARTINS, E.; SILVA, O. Influência de stock options no conservadorismo contábil. In: CONGRESSO USP DE CONTROLADORIA E CONTABILIDADE, 12., 2012, São Paulo. Anais... São Paulo: USP, 2012.

SILVA, A. C. et al. Qualidade informacional dos lucros das firmas monitoradas por agências reguladoras no Brasil. In: CONGRESSO USP DE CONTROLADORIA E CONTABILIDADE, 9., 2009, São Paulo. Anais... São Paulo: USP, 2009.

SILVEIRA, A. M. Governança corporativa, desempenho e valor da empresa no Brasil. 2002. $152 \mathrm{f}$. Dissertação (Mestrado em Administração) - Faculdade de Economia, Administração e Contabilidade, Universidade de São Paulo.

WATTS, R. L. Conservatism in accounting part I: explanations and implications. Accounting Horizons, v. 17, n. 3, p. 207-221, set. 2003.

WATTS, R. L., ZIMMERMAN, J. L. Positive Accounting Theory. New Jersey: Prenticew-Hall, 1986. 